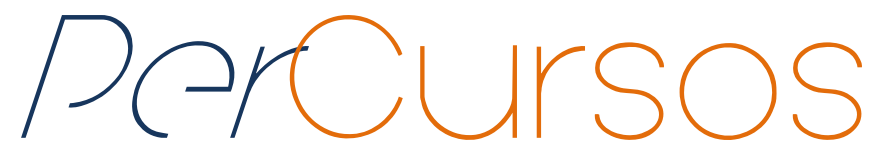

\title{
Histórias compartilhadas: propostas universitárias de construção de conhecimentos decolonizados
}

\begin{abstract}
Resumo
Nos últimos anos, tem-se ampliado no Brasil as atividades universitárias em torno dos campos dos estudos africanos e indígenas, o que tem contribuído para a visibilização de diversas experiências destes sujeitos históricos. Este alargamento deve ser atribuído, entre outras questões, à promulgação das leis federais 10.639/2003 e 11.645/2008, que instauraram a obrigatoriedade do ensino de história e cultura africana, afro-brasileira e indígena nas escolas brasileiras. Constata-se, no entanto, a permanência de uma concepção eurocêntrica/colonial sobre o mundo que resulta no epistemicídio, ou seja, na invisibilidade e exclusão de saberes e histórias das Áfricas e Américas. Embora avanços tenham ocorrido, ainda é necessário o questionamento do saber epistêmico ocidental/colonial e a valorização das teorias e epistemologias do sul que pensam com e a partir de corpos e lugares étnicoraciais/sexuais subalternizados. Nesse sentido, o objetivo deste artigo é refletir sobre experiências que estão em busca da construção de epistemologias outras, inserindo como exemplo atividades de ensino, pesquisa e extensão desenvolvidas no âmbito do Laboratório de Estudos Pós-coloniais e Decoloniais - AYA (UDESC/FAED). São as questões teóricas colocadas pelos estudos pós-coloniais e decoloniais que fundamentam as ações voltadas à produção de um conhecimento comprometido com a interpretação decolonizada acerca das histórias das sociedades africanas e indígenas.
\end{abstract}

Palavras-chave: História. África. Indígenas. Estudo e Ensino.

\author{
Para citar este artigo: \\ MORTARI, Cláudia; WITTMANN, Luisa Tombini. Histórias compartilhadas: propostas universitárias de \\ construção de conhecimentos decolonizados. Revista PerCursos, Florianópolis, v. 19, n.39, p. 154 - 176, \\ jan./abr. 2018.
}

DOI: 10.5965/1984724619392018154

http://dx.doi.org/10.5965/1984724619392018154 


\title{
Shared histories: scholarly proposals for decolonized knowledge building
}

\begin{abstract}
In the last few years, the academic productions around the field of African and indigenous studies have been expanded in Brazil, which has contributed to the visibility of the various experiences of these historical subjects. This expansion should be attributed, among other things, to the enactment of the federal laws $10.639 / 2003$ and 11.645/2008, which established the obligation of African, Afro-Brazilian and indigenous history and culture teaching in all country's schools. However, is possible to observe the permanence of a eurocentric/colonial conception on the world resulting in an epistemicide, that is, in the invisibility and exclusion of local knowledge and histories in Africas and Americas. Although advances have still occurred, it is necessary to question western/colonial epistemic knowledge and the discovery and appreciation of Southern theories and epistemologies that think with and from subalternized ethnic-racial/sexual bodies and places. In this sense, the goal of this article is to point out experiences of development of practices in the field of History of Africa and Indigenous History that are in search of the construction of alternative epistemologies, including as an example teaching, research and extension activities developed within the framework of the Laboratory of Postcolonial and Decolonial Studies - AYA (UDESC/FAED). These are the theoretical questions asked by postcolonial and decolonial studies that grounds the actions directed to the production of an academic and scientific knowledge, committed to the decolonized interpretation about the histories of African and indigenous societies.
\end{abstract}

Keywords: African Studies. Indigenous History. Postcolonial and Decolonial Studies. 


\section{Colonialidade e violência epistêmica: qual o lugar das histórias africanas e} indígenas?

O nascimento da história como disciplina, ao longo do século XIX, implicou na profissionalização de um conhecimento específico que se legitimou enquanto ciência mestra da vida, que direciona o presente para um futuro de progresso. No caso específico do Brasil, a ideia do desdobramento de uma civilização branca e europeia no Novo Mundo, ou nos trópicos, desqualificou as populações de origem africana e indígenas, consideradas opostas ao modelo. O Instituto Histórico e Geográfico Brasileiro (IHGB), espaço privilegiado desta narrativa historiográfica, definiu uma ideia de Nação brasileira que se reconhece enquanto continuadora de uma tarefa civilizadora iniciada pela colonização portuguesa (Guimarães, 1988). Concepção esta que contribuiu para a consolidação de um Estado monárquico constitucional com unidade territorial, poder centralizado no Rio de Janeiro, que manteve a escravidão e coroou o filho e, posteriormente, o neto de um rei português da Casa de Bragança.

É importante identificar a inter-relação entre o Estado e a historiografia a partir do Brasil, pois é o nosso local de atuação acadêmica e educacional. Aliás, necessário pontuar que nossos conhecimentos são sempre situados, e estudiosos (DUSSEL, 2001; MIGNOLO, 2003, 2005) nos lembram de que falamos a partir de um determinado lugar situado nas estruturas de poder e, portanto, estamos circunscritos às hierarquias de classe, sexuais, de gênero, espirituais, linguísticas, geográficas e raciais do "sistema-mundo patriarcal/capitalista/colonial/moderno". Neste sentido, como nos aponta o crítico literário indiano Homi Bhabha (1998), nossos espaços de enunciação não devem ser definidos pela polaridade dentro/fora, mas vistos como compostos por divisões, no entremeio das fronteiras que definem quaisquer identidades coletivas. É vital, portanto, o exercício de pensar como foi arquitetada uma história do Brasil que ignora histórias que Ihes são constitutivas, como as de África e das próprias populações afro-brasileiras e nativas ameríndias. Esta construção tem uma história, e precisamos compreendê-la visando contribuir para a proposição de paradigmas e epistemologias que incorporem perspectivas indígenas, africanas e afrodiaspóricas, que são inclusive transnacionais. A linha evolutiva de uma história linear relegou os indígenas ao passado exotizado e 
classificou os africanos(as) e seus descendentes, a partir da perspectiva racial, como empecilhos do progresso, sendo o papel civilizador assegurado pela presença branca. Forjou-se, assim, uma nacionalidade absolutamente excludente, uma Nação homogênea falaciosa.

A racionalidade enquanto cânone, efeito do conveniente chamado Século das Luzes, ou lluminismo, é permanência no tempo presente. A prática historiográfica oitocentista reverbera, por exemplo, na escrita e no ensino das histórias de Áfricas e Américas contemporâneas, ainda sustentados por alicerces intensa e intencionalmente eurocêntricos. A suposta marcha da humanidade estabeleceu seu vértice, a Europa, e inventou assim "os outros”, aqueles que estariam num estágio baixo de desenvolvimento humano. Esta visão inferioriza, situa histórias e culturas distintas num início de uma trajetória única cujo ponto de referência de partida e de chegada é a Europa. Portanto, da perspectiva epistemológica, o saber e as histórias locais europeias foram vistos como projetos globais (MIGNOLO, 2003, p. 41). Neste sentido, modernidade e colonialidade acabaram projetando um imaginário perante nações, corpos, ofícios e saberes, provocando a expropriação e a exclusão, a invisibilidade e a renegação de histórias locais e experiências nas Áfricas e Américas (ANTONACCI, 2013).

O intelectual colombiano Santiago Castro-Gómez aponta para o impacto deste "projeto da modernidade", sendo as Ciências Sociais fundamentais no controle da vida humana como legitimadoras das políticas reguladoras do Estado moderno disciplinador. Instituições estatais legitimadas pela letra/escrita orientam condutas a partir de um modelo de sujeito desejável que é homem, branco, casado, católico e heterossexual. O leque excludente é amplo.

A construção do imaginário da "civilização" exigia necessariamente a produção de sua contraparte: o imaginário da "barbárie". Trata-se em ambos os casos de algo mais que representações mentais. São imaginários que possuem uma materialidade concreta, no sentido de que se ancoram em sistemas abstratos de caráter disciplinar como a escola, a lei, o Estado, as prisões, os hospitais e as ciências sociais. É precisamente este vínculo entre conhecimento e disciplina o que nos permite falar, seguindo Gayatri Spivak, do projeto da modernidade como 
o exercício de uma violência epistêmica. (Grifo nosso. CASTRO-GÓMEZ, 2007, p. 82)

A contrapartida do surgimento dos Estados Nacionais é a consolidação do colonialismo europeu nos além-mares, com experiências profundamente violentas. Os processos europeus não são autônomos, como insistiram as Ciências Sociais. A Europa se construiu enquanto exclusiva portadora, criadora e protagonista da modernidade e da racionalidade. Perspectiva esta que se alastrou neste novo padrão mundial de poder (QUIJANO, 2005, p. 122). A colonialidade é constitutiva da modernidade; são, portanto, faces de uma mesma moeda (MIGNOLO, 2003). Diferencia hierarquicamente o chamado colonizador do colonizado, sendo a noção de "raça" importante nesse processo de construção de identidades que se opõem e que justificam a dominação colonial. Povos originários e escravizados foram inferiorizados em seus traços fenotípicos e descobertas mentais e culturais, legitimando uma "divisão racial do trabalho" (QUIJANO, 2005). A modernidade foi responsável pela produção de sociedades, culturas e seres humanos marginais (MUDIMBE, 2013, p. 18). As Ciências Sociais, nesse sentido, se ancoram em dicotomias essencialistas ou categorias binárias como barbárie e civilização, tradição e modernidade, mito e ciência, oral e escrito.

O pensamento e a estrutura universitária, nos alerta Castro-Gómez em outro impactante texto, é parte da estrutura triangular da colonialidade: colonialidade do poder, colonialidade do ser e colonialidade do saber (CASTRO-GÓMEZ, 2007). É o espaço privilegiado da produção e da fiscalização do conhecimento, papel atualmente assumido pelo mercado global capitalista. A consolidação do modelo epistêmico moderno/colonial, ainda hegemônico, quebrou uma visão orgânica do mundo a partir de 1492. O homem, ao se considerar elemento à parte da natureza, passa a buscar insistentemente dominá-la, exercendo, assim, um controle racional sobre o mundo que percebe a realidade de forma compartimentada. As disciplinas são fragmentadas, criam seus cânones, e se isolam. Aliás, como nos alerta Mudimbe, filósofo africano de nacionalidade congolesa: " $A$ questão em causa é que, até agora, tanto intérpretes ocidentais como analistas africanos têm vindo a usar categorias de análise e sistemas conceptuais que dependem de uma 
ordem epistemológica ocidental” (MUDIMBE, 2013, p. 10). No entanto, provoca CastroGómez, mudanças são possíveis através da flexibilização transdisciplinária e da transculturização do conhecimento. O diálogo de saberes, a convivência de diferentes formas culturais de conhecimento sem que estejam submetidos à hegemonia da episteme ocidental, seria um dos caminhos para a árdua empreitada de decolonização da universidade (CASTRO-GÓMEZ, 2007, p. 87).

É evidente que a história colonial reprimiu "em variáveis medidas de acordo com os casos, as formas de produção de conhecimento dos colonizados, seus padrões de produção de sentidos, seu universo simbólico, seus padrões de expressão e de objetivação da subjetividade" (QUIJANO, 2005, p. 121). As marcas da colonialidade do poder, do saber e do ser se revelam, como visto, nas instituições escolares nas quais o eurocentrismo se mantém como perspectiva hegemônica de conhecimento mas, também, de ser e estar no mundo. É urgente, nesse sentido, que novas práticas educacionais e de construção do conhecimento sejam construídas nas Américas sobre histórias não europeias, nem por isso desconectadas da Europa, mas em uma postura de descentralizá-la enquanto lugar de referência única para pensar sobre o mundo. Afinal, como apontou o escritor africano de nacionalidade nigeriana Chinua Achebe (2007), todos possuem o direito de buscar aquilo que denominou de "equilíbrio das histórias", ou seja, de contar as próprias histórias a partir das suas vivências, contrapondo-se à herança da colonialidade que difunde a ideia da existência de uma história única - a partir do ponto de vista eurocentrado.

É mesmo possível propor outras possibilidades de práticas educativas e de produção de conhecimentos em uma estrutura colonial?

Não se pretende aqui oferecer respostas fechadas ou certezas absolutas, mas reflexões a partir de experiências concretas em atividades de ensino, pesquisa e extensão desenvolvidas no Laboratório de Estudos Pós-coloniais e Decoloniais. ${ }^{1}$ O AYA congrega

\footnotetext{
${ }^{1}$ O laboratório é vinculado ao Departamento de História do Centro de Ciências Humanas e da Educação (FAED) da Universidade do Estado de Santa Catarina (UDESC) e iniciou suas atividades em julho de 2016. Integram sua equipe professores(as) do Departamento de História da UDESC e de outras universidades; professores(as) da rede pública de ensino, estudantes de graduação e pós-graduação da área das Ciências
} 
discentes de graduação e pós-graduação em História² e pesquisadores(as) vinculados aos campos dos Estudos Africanos e da História Indígena que estão em busca da construção de um conhecimento acadêmico, científico e social comprometido com a interpretação decolonizada acerca das experiências de diversos sujeitos sociais.

\section{A produção do conhecimento e a troca de saberes na indissociabilidade}

\section{entre ensino, pesquisa e extensão}

As ações desenvolvidas no Laboratório AYA partem de um pressuposto central: 0 questionamento do saber epistêmico ocidental/colonial e a valorização das teorias e epistemologias do sul que pensam não somente sobre, mas, sobretudo, com e a partir de corpos e lugares étnico-raciais/sexuais subalternizados. A intenção é, efetivamente, deslocar o lugar a partir do qual alguns paradigmas são pensados e, em especial, dois deles: a existência de uma hierarquia epistêmica que coloca os conhecimentos ocidentais num local privilegiado em relação ao conhecimento e às cosmologias não ocidentais, sendo esta hierarquia institucionalizada no sistema universitário global (MIGNOLO,2003; QUIJANO, 2005); a existência de uma hierarquia que privilegia a comunicação, a produção do conhecimento, de teorias europeias e que subalterniza as não europeias colocando-as como produtoras de folclore ou cultura, mas não de conhecimento/teoria (MIGNOLO, 2003). Tais perspectivas implicam, sobremaneira, no exercício da crítica às antigas dicotomias periferia/centro; cosmopolitismo/ruralismo, civilizado/selvagem, negro/branco, norte/sul, num contexto cultural de globalização.

A produção de saberes de africanos nas Áfricas, de seus descendentes na diáspora e das populações originárias constroem-se na contramão desses cânones ocidentais. As narrativas e as estéticas, as dinâmicas de expressão e reconhecimento de histórias, de

Humanas e integrantes vinculados a movimentos sociais. Aya é uma palavra adinkra (povos akan) para samambaia, cujo símbolo significa perseverança e resiliência. Ver: <http://www.faed.udesc.br/?id=2395>.

${ }^{2}$ No ano de 2017, os(as) discentes de graduação vinculados aos projetos desenvolvidos pelo AYA eram os seguintes: Bruna Maria Antunes, Cadídja Assis Pinto, Daniele Policarpi, Emílio Ranieri Migliorini, Emmanuel Fernandez da Silva, Katarina Kristie Martins Lopes Gabilan, Luciana Madeira Caetano, Marina Fernandes Gonsalves, Matheus Albuquerque Flores, Rodrigo Ferreira dos Reis, Stéfani Dias Leite e Willian Felipe M. Costa. Agradecemos a cada um(a) pelo trabalho e parceria. 
lutas e de memórias destes grupos subalternizados estão a desalojar conhecimentos continentais engessados e fechados em si mesmos (ANTONACCl, 2013, p. 248). Como muito bem nos lembra Franz Fanon:

No momento em que desejo, estou pedindo para ser levado em consideração. Não estou meramente aqui-e-agora, selado na coisitude. Sou a favor de outro lugar e de outra coisa. Exijo que se leve em conta minha atividade negadora na medida em que persigo algo mais do que a vida, na medida em que de fato batalho pela criação de um mundo humano - que é um mundo de reconhecimentos recíprocos. Eu deveria lembrar-me constantemente de que o verdadeiro salto consiste em introduzir a invenção dentro da existência. No mundo em que viajo, estou continuamente a criar-me. E é passando além da hipótese histórica, instrumental, que iniciarei meu ciclo de liberdade. (FANON apud BHABHA, 1998, p. 30)

É importante ressaltar que concebemos as ações universitárias enquanto um lócus de exercício de prática docente, de pesquisa e de extensão indissociáveis e articuladas a partir de uma relação dialógica com a sociedade. Dessa forma, articula-se teoria e prática na produção do conhecimento, da sua democratização, bem como, para a formulação de concepções e ações curriculares visando a transformação das práticas sociais.

Os projetos de extensão ${ }^{3}$ universitária desenvolvidos no ano de 2017 no Laboratório AYA abarcam a realização de rodas de saberes/conversas com migrantes

\footnotetext{
${ }^{3}$ Os Programas de Extensão desenvolvidos visam a troca, produção, transmissão e a apropriação de campos do conhecimento, em especial, das ciências sociais, humanas e políticas vinculadas à temática dos estudos africanos e indígenas. Possuem abrangência nacional, interinstitucional, têm por objetivo, também, desenvolver ações que auxiliem na implementação das Leis Federais 10.639/03 e 11.645/2008 e das Diretrizes Nacionais de Educação para as Relações Étnico-Raciais e História e Cultura Afro-Brasileira e Africana (Diretrizes de 2004) e das Diretrizes Operacionais para Implementação da História e das Culturas dos Povos Indígenas na Educação Básica em decorrência da Lei n 11645/2008 (Diretrizes 2016). São desenvolvidos em parceria com instituições federais e municipais da rede oficial de ensino, laboratórios da FAED/UDESC, coletivos africanos e indígenas e movimentos sociais. Possuem como público-alvo educadores(as), alunos(as), gestores(as) públicos, acadêmicos(as) de licenciaturas e bacharelado, pesquisadores da área de História, de Educação, de Artes e demais interessados. Dois Programas foram desenvolvidos no ano de 2017, contendo três ações em cada um deles: Programa Histórias Africanas e Indígenas: olhares e práticas na educação, coordenado pela Prof. ${ }^{a}$ Claudia Mortari e o Programa Olhares, vozes e memórias: saberes africanos e indígenas, coordenado pela Prof. ${ }^{a}$ Luisa Tombini Wittmann.
} 
africanos e indígenas ${ }^{4}$; elaboração de materiais didáticos sobre os temas da diversidade ${ }^{5}$ e história de África; criação de biblioteca virtual da temática africana e indígena; organização de mostra de filmes e documentários produzidos por (ou em conjunto com) indígenas e africanos e produção de um vídeo que aborda o tema da educação pela perspectiva dos alunos do magistério indígena de Santa Catarina. ${ }^{6}$ Das atividades de ensino, destacamos as disciplinas de: Prática Curricular: Ensino de História e suas linguagens I e II, História da África I e II e História Indígena, na graduação; de Ensino (d)e História Indígena e Ensino de História e Cultura Africana e Afro-Brasileira, ambas no Mestrado Profissional em Ensino de História (ProfHistória) da UDESC ${ }^{7}$. As disciplinas possuem como perspectiva fundamental o deslocamento de um conhecimento eurocentrado através do diálogo com uma produção do Sul Global ${ }^{8}$. Tal ponto de vista se apresenta, também, nos projetos de pesquisa que se concentram nas investigações em torno da literatura do escritor nigeriano Chinua Achebe e do ensino de história indígena

\footnotetext{
${ }^{4}$ Os cinco encontros realizados no ano de 2017 contaram com a participação de 330 pessoas no total. A estreia das ações de extensão ocorreu no dia 27 de março com lotação máxima do auditório Tito Sena (Faed-Udesc), quando foi exibido e debatido o filme Bicicletas de Nhanderú. A liderança indígena Marcos Karaí proferiu na ocasião uma impactante palestra sobre educação e espiritualidade Guarani. $O$ encerramento se deu no dia 30 de novembro com o Prof. Dr. Clint Le Bruyns versando sobre o tema "Solidariedade sul-africana na luta por libertação palestina". O palestrante atua na universidade de KwaZulu-Natal em África do Sul, participando ativamente nas redes de apoio e solidariedade na luta por direitos do povo palestino.

${ }^{5}$ Esta produção de material didático se constitui na construção de livros de histórias (advindos do trabalho com oficinas didáticas com professores da rede de ensino e estudantes de graduação em História vinculados à Disciplina de prática Curricular: Ensino de História e Suas Linguagens II) cujo tema central é a diversidade e que tem como objetivo possibilitar aos estudantes do ensino fundamental a compreensão da existência de diferentes formas de ser e estar no mundo. Neste sentido, foram construídas cinco histórias de crianças que pertencem a grupos étnico-raciais diversos: Théo e Violeta, afrodescendentes; Lara, que pelo lado materno da família possui descendência nipo-brasileira, e pelo lado paterno, descendência Boliviana; Nina, descendente de indígenas da etnia Guarani; Luan, descendente de imigrantes Europeus. A partir das narrativas criadas, que expressam vivências das personagens em seus cotidianos é possível construir concepções acerca da diversidade. O projeto é coordenado pela Profa. Bárbara Giese.

${ }^{6}$ O vídeo "Saberes Compartilhados: magistério indígena de Santa Catarina" foi realizado junto aos discentes deste curso de formação de professores em parceria com a Retrato Ateliê de Narrativas Multimídia, tendo as filmagens ocorrido durante etapas de estudo em Florianópolis e na aldeia Guarani do Morro dos Cavalos. O curso, oferecido pela Secretaria de Estado da Educação-SC, abarca estudantes das três etnias existentes no estado: Guarani, Kaingang e Xoklen-Laklánõ. Ver https://bit.ly/2HEMs7L

7 História Indígena e Ensino (d)e História Indígena são ministradas pela Prof. ${ }^{a}$ Luisa Tombini Wittmann. História da África I e II e Ensino de História e Cultura Africana e Afro-Brasileira, ministradas pela Prof. ${ }^{a}$ Claudia Mortari. Prática Curricular: Ensino de História e suas linguagens I e II são ministradas pela Prof.a Bárbara Giese.

${ }^{8}$ Epistemologias do Sul não se refere a um recorte geográfico, mas sim a saberes, viveres, ideias de sujeitos subalternizados pelo pensamento eurocêntrico/colonial/moderno (MIGNOLO, 2003).
} 
nas universidades catarinenses. São ações diversas, porém articuladas, que se amparam na indissociabilidade entre ensino, pesquisa e extensão universitária.

Especificamente sobre as ações de extensão que promovem rodas de conversas e produção, exibição e debate de audiovisuais, é importante ressaltar que, diferente da textualidade, a linguagem (áudio)visual trabalha com a presença do corpo e do gesto, elementos essenciais, como aponta a estudiosa da cultura afro-brasileira Maria Antonieta Antonacci (2013), às formas de contar de culturas orais. Trata-se de um alargamento de linguagens e narrativas históricas, necessário para a construção de epistemologias novas. Aos perigos da história única, descritos por Chimamanda Adichie, poderíamos acrescer as consequências de uma história exclusivamente escrita.

Diversas comunidades indígenas Brasil afora têm buscado no vídeo, na fotografia e em narrativas sonoras formas de registrar sua própria cultura e história. São formatos com potencial para criar identificações, além de assumir o gesto e o corpo das populações cuja história é contada. Há ricos materiais resultantes de oficinas junto aos povos indígenas, que têm o processo colaborativo em seu cerne, nos quais estes escolheram o tema, interpretaram, filmaram e foram protagonistas da história. Optaram, enfim, por uma linguagem que Ihes é mais interessante e a utilizam inclusive nas suas lutas políticas cotidianas e na educação escolar indígena diferenciada, que, aliás, usufrui de outros materiais além do livro. Tal perspectiva tem sido expressa também em produções fílmicas e em documentários referentes a diversas regiões e populações do continente africano. Emblemático é o caso do cinema africano (produzido em África e realizado por africanos), utilizado como instrumento de crítica ao colonialismo europeu e de formas narrativas que são inspiradas em histórias e mitos locais. Aliás, um dos principais nomes de referência, Sembène (Senegal) sempre confrontou seus espectadores "com personagens que questionam a ordem natural do mundo à sua volta, exigiam mudança e desafiavam a nossa visão de África enquanto continente fora da história" (DIAWARA, 2011, p. 22). Conforme Marcelo Ribeiro, um dos propósitos do cinema africano consiste não somente na busca de imagens outras de África e de suas paisagens culturais, mas, sobretudo, na reivindicação de narrar. 
Diante do exotismo colonialista que se prolonga no regime ocidentalista de escritura da 'África' e se investe com o que Edward Said chama de "poder de narrar" (e, portanto, de excluir outras narrativas), os cinemas africanos têm como impulso originário, mesmo que eventualmente subterrâneo e inconsciente, a reivindicação do direito de narrar. Eis a sua condição política originária. No entanto, se todos os cinemas africanos carregam a potência política da reivindicação do direito de narrar, o cinema político africano pode ser identificado naqueles filmes que interrogam e exploram (de forma consciente, por assim dizer) a questão da política da narrativa como condição originária de sua própria existência. (RIBEIRO, 2011)

Neste sentido, o compartilhamento de histórias em suportes orais e audiovisuais tem o objetivo principal de apresentar versões plurais e complexas, africanas e indígenas, formuladas a partir de seus próprios olhares, com usos de ferramentas narrativas adequadas aos seus anseios. Entendemos que este é um caminho importante para a construção da diversidade praticada, rumo ao que poderíamos chamar de um "equilíbrio das histórias", através dos quais estas populações deixam de ocupar espaços predeterminados nas narrativas escritas sobre o passado para tornarem-se sujeitos ativos não só da história, mas de suas formas de fazer e contar. A linguagem oral e audiovisual se torna, assim, canal construtivo de empatia. O processo de geração de empatia acontece quando a narrativa nos transporta para o mundo da personagem, fazendo com que nos identifiquemos com ela, com seu grupo, com suas lutas. A implementação das leis federais 10.639/03 e 11.645/08 ${ }^{9}$ depende de uma compreensão de histórias e culturas africanas e indígenas que seja fruto desse processo educativo e do reforço e da efetivação de suas reivindicações políticas. Portanto, concebemos que não se trata apenas da inclusão de conteúdos mas, principalmente, de pensar perspectivas epistemológicas e paradigmas outros.

A pesquisa “Ensino de História Indígena: realidade, desafios e possibilidades” tem demonstrado que estamos distantes de um conhecimento decolonial. O objetivo geral da

\footnotetext{
${ }^{9}$ O sistema de educação brasileiro é regulamentado pela Lei de Diretrizes e Bases da Educação Nacional (LDB) promulgada sob o número 9.394/1996. A lei 10.639/03 alterou um dos artigos da LDB e que foi modificada novamente pela lei 11.645/08, que institui a obrigatoriedade do ensino de história e cultura afro-brasileira e indígena. Ao longo do texto, no entanto, optamos por citar as duas leis, em especial porque a 10.639/03 possui sua importância histórica e política relacionada às lutas dos movimentos contemporâneos negros.
} 
pesquisa é investigar os conhecimentos relacionados à temática indígena nos componentes curriculares dos cursos de História das Instituições de Ensino Superior do Estado de Santa Catarina. Entendemos que sem formação adequada de professores não há efetivação plena da legislação educacional e, portanto, os cursos de licenciatura precisam se adequar e colaborar com a efetivação da lei 11.645/08. Ao longo de dois anos de pesquisa, foram realizadas coleta, organização e análise sobretudo da seguinte documentação: projetos de curso (projeto político-pedagógico ou projeto pedagógico do curso) e planos de ensino das disciplinas de história e cultura indígena (e similares), além de estudo bibliográfico que incluiu a produção dos docentes.

A análise dos projetos pedagógicos dos cursos e dos planos de ensino da disciplina História Indígena (quando há) tem revelado, dito de maneira breve, que tais cursos seguem o modelo quadripartite francês, sendo marcante a carência de materiais que contemplem histórias e culturas indígenas para além da disciplina específica. Devemos ressaltar, no entanto, a inclusão da disciplina de História Indígena em 42\% dos cursos de História, sendo que todas enfatizam a relevância da implementação da lei 11.645/08 e se propõem a articular as questões de ensino com o conteúdo histórico, fortificando assim a formação desses alunos enquanto futuros professores responsáveis e conscientes de sua atuação profissional na sociedade brasileira contemporânea. Apesar das distinções evidentes nas propostas e mesmo na atuação individual dos docentes, a agência indígena em diferentes temporalidades e regiões do Brasil se mostrou frequente nos planos de ensino analisados. No entanto, entendemos que seria importante que mais produções indígenas fossem trabalhadas nas disciplinas. É importante o reconhecimento dos indígenas enquanto agentes transformadores da história, mas mais do que isso, também como produtores de conhecimento.

Ainda que tenhamos um caminho árduo na superação de um conhecimento hegemônico eurocêntrico, a presença desta disciplina como obrigatória nos cursos de História (e em outros) é fundamental para que se ampliem cada vez mais os olhares acerca dos povos indígenas, possibilitando pensar uma história e historiografia que os contemple como sujeitos a partir de suas próprias visões históricas. Algumas iniciativas desenvolvidas nas universidades públicas, comunitárias e privadas catarinenses merecem 
ser destacadas, entre elas a apresentação de narrativas indígenas, que compreende a escolha de um material que pode ser musical, fílmico, literário, audiovisual, entre outros, desde que produzido por indígenas. As representações das populações indígenas nos materiais escolares também foram analisadas; a compreensão e a análise dos livros didáticos como documentos históricos estimulam que os futuros professores trabalhem a temática indígena com criticidade. O intuito é refletir sobre o uso desses materiais textuais e imagéticos em sala de aula, em busca de romper com o estereótipo do "índio", o que pode ocorrer também através de visitas às aldeias indígenas, proposta também presente por alguns planos de ensino da disciplina História Indígena. Essa vivência é muito interessante para a reflexão e ação de acordo com a realidade específica de cada região e com as demandas sociais indígenas, no caso de Santa Catarina, Guarani, Kaingang e Xokleng-Laklãnõ.

Outra atividade avaliativa analisada foi a elaboração de planos de aula e de material didático sobre a temática indígena pelos licenciandos, que têm potencial para serem utilizados tanto no estágio docência quanto em sala de aula, quando se tornarem professores. Destacamos a produção de jogos analógicos e digitais, que envolvem alunos(as) de diversas idades, tornando-os partícipes do processo de ensinoaprendizagem de maneira lúdica. Essa forma de avaliação, portanto, colabora na formação dos futuros professores do ensino básico combatendo dois dos maiores desafios inerentes à implementação da lei 11.645/08, a saber: formação na área e materiais didáticos atualizados. Há outros desafios a serem realmente encarados, como inspiram Edson Kayapó e Tamires Brito:

Está lançado o convite para empreendermos um caminho docente que repense a natureza e o lugar da nossa atividade de professor na educação básica, assumindo o compromisso social e político próprio do ofício, buscando avançar na produção de outras histórias, baseadas em outras memórias dos povos indígenas, ancoradas na relação temporal presente-passado e presente-futuro. (KAYAPÓ, BRITO, 2014, p. 41) 
O ensino de história indígena na universidade apresenta um avanço, porém é necessário ainda o alargamento da reflexão a partir de materiais de autoria indígena, de preferência oriundos de grupos distintos. Dessa forma, a sociedade perceberá a riqueza da diversidade indígena, afinal, são mais de trezentos povos apenas no Brasil. Isso possibilita ir além de questões básicas e gerais ao estudar aspectos específicos de histórias e culturas de diferentes povos originários. E, mais do que isso, incorporar perspectivas indígenas. Em que medida epistemologias indígenas nos fazem (re)pensar nossa prática e (re)construir o conhecimento? Questões como essa evidenciam o quanto o caminho é longo, mas frutífero. Principalmente se, de fato, aprendermos com os indígenas sobre sua própria história, sobre a nossa história.

É necessário e urgente superar a concepção positivista/evolucionista resultante do processo colonialista de nossa história ultrapassando os estereótipos ainda vigentes acerca das populações indígenas e de origem africana em uma sociedade que tem como marca a diversidade. Neste sentido, entendemos ser essencial a discussão de bibliografias e de outros materiais produzidos pelos próprios indígenas e africanos em salas de aula de escolas e universidades, ou seja, partir dos seus conhecimentos. A real efetivação das leis e diretrizes educacionais, e a consequente formação de uma sociedade mais inclusiva, necessita construir novas concepções de ensino-aprendizagem através de uma educação intercultural.

No que concerne ao campo dos chamados estudos africanos, em que pese à contribuição dos dispositivos legais (MORTARI, 2016) e da ampliação do campo e dos temas de pesquisa, existem, entre tantas outras, duas questões que nos parecem centrais e que precisam ser problematizadas, pois impactam na construção do conhecimento e da prática pedagógica. A primeira delas, diz respeito à existência de uma visão racializada e essencializada das populações africanas, acionada tanto no sentido de inferiorização quanto de positivação que acaba por construir uma perspectiva heterogênea acerca de populações tão diversas. A permanência de uma visão racialista é proveniente de uma concepção eurocêntrica/colonial/moderna sobre o mundo (MIGNOLO, 2003). Como coloca, Appiah: 
Se nos fosse possível viajar pelas muitas culturas da África naqueles anos - desde os pequenos grupos de caçador-coletores bosquímanos, com seus instrumentos da Idade da Pedra, até os reinos haussás, ricos em metais trabalhados -, teríamos sentido, em cada lugar, impulsos, ideias e formas de vida profundamente diferentes. Falar de uma identidade africana no século XIX - se identidade é uma coalescência de estilos de conduta, hábitos de pensamento e padrões de avaliação mutuamente correspondentes (ainda que às vezes conflitantes), em suma, um tipo coerente de psicologia social humana -, equivalia a dar a um nada etéreo um local de habitação e um nome. (APPIAH, 1997, p. 243)

A segunda está relacionada, especificamente, à expansão das pesquisas e dos estudos no Brasil acerca da História da África. Em que pese a existência de diferentes perspectivas de análise e a sua contribuição para a produção e difusão do conhecimento, ainda há muito que se produzir a partir de um diálogo com pesquisadores africanos e da ampliação dos documentos históricos utilizados. Aliás, como nos alerta o filósofo Hountondji:

quão africanos são os chamados estudos africanos? Por exemplo, por história africana entende-se normalmente o discurso histórico sobre África, e não necessariamente um discurso histórico proveniente de África ou produzido por africanos. Em termos gramaticais, referimo-nos à história de África (...). (HOUNTONDJI, 2010, p. 133)

Diante de tal assertiva, o autor salienta a necessidade dos(as) pesquisadores(as) africanos desenvolverem uma "tradição de conhecimento em todas as disciplinas e com base em África" (HOUNTONDJ, 2010, p. 141). Por outro lado, acadêmicos(as) não africanos poderiam contribuir a partir da sua própria perspectiva e contexto histórico.

Estas questões, entre outras, constituíram as reflexões que resultaram na proposição da pesquisa “Modos de ser, ver e viver: o mundo lbo a partir da escrita de Chinua Achebe (África Ocidental, séc. XX), que tem como documentos as obras literárias do escritor nigeriano ${ }^{10}$ escritas no contexto da independência da Nigéria. Intenciona-se, a partir das suas obras literárias, compreendidas aqui como evidências históricas, apontar a

\footnotetext{
${ }^{10}$ O Mundo se Despedaça, 1958; A Flecha de Deus, 1964; A Paz Dura Pouco, 1960.
} 
perspectiva do escritor ao narrar os modos de ser, ver e viver do mundo lbo, acerca do colonialismo e do processo de independência na Nigéria. Entre as muitas questões que nos intrigam, algumas nos parecem centrais. Como o escritor vai evidenciar as ações e visões de mundo dos seus diferentes personagens? Como compreender as dinâmicas sociais, os contatos entre igbos e europeus no contexto? O que o autor e a sua escrita nos permite desvendar do processo histórico? Quais tradições culturais são instituídas e reproduzidas na sua obra? As obras de Achebe estão profundamente informadas por sua visão e sentidos da história.

Nascido na Nigéria, na aldeia de Ogidi, em Igboland, na década de 1930, trinta anos antes da libertação do domínio colonial britânico, Achebe tem ao longo de sua carreira cerca de trinta livros (romances, contos, ensaios e poesia). De forma geral, as narrativas das obras elencadas para a nossa análise e diálogo versam acerca da inferiorização que o ocidente imprimiu às sociedades e culturas africanas, os efeitos da colonização do continente pelos europeus, mas também uma crítica aberta à política nigeriana no contexto da independência e, portanto, à colonialidade do poder, do saber e do ser. Além disso, trazem marcas da tradição oral, os vocábulos, os provérbios lgbo da região onde nasceu.

Para Achebe, preocupado com assuntos sociais e políticos que vão acontecendo, sobretudo em África, a literatura tem o papel de permitir "chegar à vida das pessoas para quem escrevo: eu conto o que acontece nas vidas delas, os problemas que elas têm e com que políticas elas têm de lidar nos países onde vivem" (ACHEBE, 2008). Assim, pensamos que a literatura, pode apresentar evidências e indícios que possibilitem a compreensão dos processos históricos nas sociedades da costa oeste africana no contexto do século XX a partir de uma narrativa própria. Aliás, o próprio autor, em uma entrevista, declarou que sua intenção ao escrever sobre sua etnia era tornar visíveis ao mundo seus costumes e experiências históricas em contato com os colonizadores europeus, sem vitimizações e visões estereotipadas (ACHEBE, 2008). Sua escrita, inserida no campo das chamadas literaturas pós-coloniais, nascidas num contexto marcado pela colonização europeia e tendo como marca fundamental a reinterpretação do discurso colonial e a crítica aos efeitos culturais da colonização, se constitui de uma estratégia 
emblemática para frustrar a visão colonial criando possibilidade de contraposição às ideologias colonialistas (LEITE, 2012, p. 130).

O desenvolvimento da pesquisa referida anteriormente está relacionado diretamente à produção de um material didático, vinculado a uma ação de extensão, que se constitui na construção de um site interativo que tem como base a obra de Achebe "O mundo se despedaça" " Nesta, o autor narra sobre a aldeia fictícia de Umuófia, uma comunidade Igbo localizada na costa oeste africana. A personagem principal da narrativa é Okonkwo e a história se desenvolve em torno de suas experiências inseridas nas redes de relações de parentesco da aldeia: sua infância, seu prestígio alcançado na comunidade devido ao fato de ser um guerreiro e um produtor, sua família, até seu trágico fim com a chegada do colonizador britânico no fim do século XIX. Conforme apontado anteriormente, tendo como princípio que os africanos são produtores de histórias e constroem narrativas sobre si, a literatura de Achebe, devidamente problematizada e analisada, possibilita acessar indícios acerca do posicionamento e intencionalidades do escritor, circunscritos ao tempo e contexto no qual estava inserido no momento da escrita de sua obra. Mas, também, concepções e percepções sobre seus próprios legados históricos-culturais-sociais. É nesta perspectiva que construímos um material didático ${ }^{12}$ com o objetivo de contribuir para a implementação das Leis Federais 10.639/2003 e $11.645 / 2008$.

A partir da leitura da obra foram escolhidas algumas cenas do cotidiano presente na narrativa que se referem a formas de governar, de festejar, de cozinhar, de morrer e de conceber a relação com o divino. A partir das cenas, construímos textos didáticos nos quais são discutidas questões relativas: à guerra, às concepções de justiça, à territorialidade, à divisão do trabalho, às hierarquias sociais, ao comércio, à produção agrícola, à violência, à patrilinearidade, às relações de parentesco, à cosmovisão, ao

\footnotetext{
${ }^{11}$ É sua primeira e mais conhecida obra, publicada em 1958, dois anos antes da independência da Nigéria, quando ele tinha 28 anos. Traduzida para mais de cinquenta línguas, sendo o título original Things fall apart.

${ }^{12}$ Tal material foi concebido para o trabalho com estudantes a partir do sexto ano do Ensino Fundamental a partir de reuniões e discussões realizadas com professores(as) da rede de ensino de Florianópolis e com os bolsistas do laboratório, estudantes de graduação em História, vinculados ao projeto. Está em fase de finalização e será disponibilizado em formato digital na Biblioteca Virtual do AYA.
} 
colonialismo. Tais textos, embasados em estudos multidisciplinares, articulados com fragmentos da literatura e fotografias, têm como eixo central quatro conceitos principais indissociáveis para a compreensão de sociedades africanas: tradição, ancestralidade, oralidade e tempo. O material será acompanhado, também, de ilustrações que estão sendo elaboradas com base na pesquisa de imagens e nas descrições da própria literatura. Portanto, o professor ao acessar o site terá acesso à literatura, textos didáticos discutindo os elementos históricos, sociais e culturais presentes nas cenas escolhidas, imagens (fotografias de aldeias igbos na primeira metade do século XX) e ainda a um guia de orientação para o trabalho articulando história, literatura e ensino de história, podendo escolher o tema ou a abordagem que irá seguir no trabalho docente.

No que toca especificamente às experiências de ensino na disciplina de História Indígena, inserida recentemente no currículo do curso de História da UDESC, gostaríamos de ressaltar o profícuo exercício dos discentes na pesquisa, apresentação, debate e divulgação em redes sociais de narrativas indígenas como parte do processo avaliativo. Foi impactante o aprendizado dos alunos e alunas não indígenas a partir de histórias e experiências indígenas de povos diversos. Vale apontar que a maioria das narrativas discutidas são audiovisuais, como dito, largamente produzidos na atualidade pelos povos originários. A aula inicia sempre com o atento ouvir (e geralmente também ver) que revela, com efeito, elementos da complexidade e da diversidade étnico-cultural dos povos originários. A pesquisa individual prévia dos discentes já amplia percepções acerca de elementos culturais, linguísticos e históricos de sujeitos e grupos indígenas diferentes entre si. Enfatizamos, também, a produção pelos próprios alunos(as) de materiais didáticos sobre a temática indígena, que serão utilizados em sala de aula, atividade avaliativa da disciplina História Indígena do Curso de Graduação em História e da disciplina Ensino (d)e História Indígena do Mestrado Profissional em Ensino de História, ambos da UDESC.

O antropólogo Gersem José dos Santos Luciano, mais conhecido como Gersem Baniwa, nos lembra de que "não se pode respeitar e valorizar o que não se conhece. Ou pior ainda, não se pode respeitar ou valorizar o que se conhece de forma deturpada, equivocada e pré-conceitualmente" (LUCIANO, 2012, p. 141). Nesse sentido, as narrativas 
e os materiais didáticos discutidos e produzidos nas disciplinas supracitadas serão divulgados com comentários numa plataforma digital. Trata-se do projeto de extensão Biblioteca Virtual Estudos Africanos e Indígenas, que tem como objetivo compartilhar materiais sobre histórias e culturas indígenas e africanas para professores(as) e alunos(as) de escolas, graduação e pós-graduação, além de interessados em geral. Serão também divulgados online outros e diversos materiais relevantes, no intento de colaborar com a implementação da lei 11.645/08, que torna obrigatório o estudo das temáticas afrobrasileira e indígena em todo âmbito escolar brasileiro. Os quatro volumes da coleção Educação para as Relações Étnico-raciais ${ }^{13}$ (três deles organizados por nós), por exemplo, foram também divulgados por outros sites e mídias sociais, resultando em milhares de downloads.

O objetivo do site ayalaboratorio.com, portanto, consiste em divulgar e deixar acessíveis materiais audiovisuais, iconográficos e escritos cujas temáticas se refiram às histórias indígenas e das Áfricas, incluindo as produções de ensino, extensão e pesquisa desenvolvidas pelos participantes do $\mathrm{AYA}^{14}$. O site disponibiliza materiais que operam de forma conjunta, razão e emoção, sem hierarquizar o saber e o sentir, alinhando os distintos conhecimentos existentes em nossa sociedade, o que pensamos consistir em uma nova forma imprescindível de enfrentamento a um pensamento hegemônico.

No que se refere às disciplinas de História da África I e II (que compreende os períodos históricos do século XV ao XIX e o século XX, respectivamente), nossos esforços

\footnotetext{
${ }^{13}$ A Coleção "Educação para as relações étnico-raciais" é o resultado de pesquisas nas áreas da História, da Educação e da Cultura de sujeitos africanos, afro-brasileiros e indígenas e está dividida em quatro volumes: Estudos Africanos, Histórias Africanas e Afro-Brasileiras, As relações étnico-raciais na sala de aula e Protagonismo indígena na História. Trata-se de uma parceria entre UFFS, UDESC e financiada pelo FNDE e MEC/SECADI, cujo objetivo maior é a superação do racismo e das desigualdades raciais nos estabelecimentos de ensino e na sociedade em geral. A proposta da Coleção é, portanto, colaborar com a implementação das leis federais $n^{\circ} 10.639 / 03$ e ${ }^{\circ} 11.645 / 08$.

${ }^{14} \mathrm{O}$ site foi lançado em meados de outubro de 2017. Ver: <http://ayalaboratório.com>. Até abril de 2018, tivemos um total de 4.910 visitantes e $\mathbf{1 1 . 8 6 8}$ visualizações. Estas, por países: Brasil - 19.944; Estados Unidos - 405; Colômbia - 179; Portugal - 161; Alemanha - 113; Argentina - 84; Canadá - 83; México - 80; França - 76; Espanha - 55; Itália - 46; Reino Unido - 40; Chile - 31; Perú - 31; Bolívia - 28; Angola - 26; Irlanda -18; Cabo Verde -16; Uruguai - 15; Egito - 12; Hungria - 10; República Dominicana - 10; Venezuela - 8; Equador - 7; Guatemala - 6; Bélgica, Bulgária, Holanda, Senegal, União Europeia - 4; Suécia - 3; Austrália, Cuba, Nigéria, Índia, Polônia, República Tcheca, Uganda - 2; África do Sul, Cazaquistão, Honduras, Lituânia, Zimbabwe -1 .
} 
têm se centrado na proposição de referenciais de estudos que apontam as populações africanas como protagonistas e agentes de sua própria história. Mas, também, mais que isso: o seu papel central na construção de interpretações de sua experiência social e histórica. Neste sentido, o diálogo com a produção realizada pelos próprios pesquisadores(as) africanos, de caráter interdisciplinar e multidisciplinar assumindo uma postura de ouvir as suas vozes, suas criações culturais e históricas, seus conhecimentos. Como afirma o historiador Ki-Zerbo: “É aqui que será necessário transformar a educação e não [...] mantendo os conteúdos e as estruturas atuais. Como já disse há dezenas de anos, o que nós procuramos não é tanto aumentar a velocidade do trem da educação, mas mudar a direção dos trilhos" (KI-ZERBO, 2006, p. 151). Tal postura implica na inclusão de um amplo corpus documental e bibliográfico nas aulas: desde escritos filosóficos, sociológicos, históricos, perpassando pelo cinema, música, poesia. Este trabalho é realizado tendo como foco central o princípio heurístico da diversidade, de forma que seja possível construir uma interpretação e explicação da existência de contextos e sociedades diversas e complexas que constituem o continente africano. Como bem nos ensina o escritor nigeriano Chinua Achebe, que em uma de suas entrevistas afirmou ser fundamental que ocorra aquilo que livremente traduzimos como "o equilíbrio das histórias": diante de uma história que você não gosta ou que não lhe representa é preciso contar outra que a contraponha. Profundamente inspiradas pelas ideias de Achebe, consideramos necessário construir perspectivas outras acerca das Histórias de Áfricas e indígenas (e da produção do conhecimento sobre), o que se constitui num desafio epistemológico e político para todos e todas.

As propostas universitárias de construção de conhecimentos decolonizados aqui relatadas partem, portanto, de um posicionamento epistemológico e crítico à perspectiva histórica, ontológica e epistêmica. Ao criar ações que visam construir respostas alternativas de saberes outros e epistemologias outras, pretende-se problematizar a hierarquia de conhecimento estabelecida pela europeização e a globalização, ou, consoante com Grosfoguel (2008), redefinir as noções de cidadania, democracia, direitos humanos e de humanidade para além de uma perspectiva colonial/moderna. Assertiva imprescindível para a compreensão do compromisso maior da Universidade: a produção 
de conhecimento capaz de romper barreiras e provocar mudanças.

Neste sentido, partimos do princípio que a produção do conhecimento nas universidades, esse lócus de enunciação do qual fazemos parte, precisa necessariamente estar aberto para diferentes formas de ver, ser e viver o mundo, rompendo com a perspectiva de uma suposta história universal. Afinal, não possuímos uma história única, como bem alerta a escritora Chimamanda Adichie ${ }^{15}$. Precisamos caminhar no sentido de encontrar o “equilíbrio das histórias" (ACHEBE, 2008) para superar a perspectiva da colonialidade do poder, do saber e do ser. Afinal, disso depende a nossa humanidade.

Nenhuma pessoa, nenhum grupo podem ser humanos sozinhos. Nós nos erguemos acima do nível animal juntos - ou então não nos erguemos. Se aprendermos a lição, ainda que tarde, teremos dado um passo à frente, um passo verdadeiramente digno de um novo milênio. (ACHEBE, 2012, p. 167)

\section{Referências}

ACHEBE, Chinua. A Educação de uma criança sob o protetorado britânico: ensaios. São Paulo: Companhia das Letras, 2012.

ACHEBE, Chinua. O Mundo se despedaça. São Paulo: Companhia das Letras, 2009.

ACHEBE, Chinua. The Africa Report e Sable Mag Online, 27 mar. 2013. Disponível em: An interview with Late Nigerian Author, Chinua Achebe. <http://www.theafricareport.com/West-Africa/an-interview-with-late-nigerian-authorchinua-achebe-by-helon-habila.html>. Acesso em: 22 ago. 2016.

ANTONACCI, Maria Antonieta. Memórias ancoradas em corpos negros. 1.ed., São Paulo: EDUC, 2013.

APPIAH, Kwame Anthony. Na casa de meu pai: a África na Filosofia da Cultura. Rio de Janeiro: Contraponto, 1997.

BAHBHA, Komi K. O local da cultura. Belo Horizonte: Editora UFMG, 1998.

\footnotetext{
15 TEDGlobal 2009. "Chimamanda Adichie: "The danger of a single story", TED, July 2009". Retrieved 30
} August 2013. https://www.ted.com/talks/chimamanda_adichie_the_danger_of_a_single_story 
BRASIL. Lei n 10.639, de 9 de janeiro de 2003. Diário Oficial [da] República Federativa do Brasil. Brasília, DF, 9 jan. 2003. Disponível em:

<http://www.planalto.gov.br/ccivil_03/leis/2003/L10639.htm>. Acesso em 10 de agosto de 2015.

BRASIL. Ministério da Educação. Secretaria Especial de políticas de Promoção da Igualdade Racial. Diretrizes curriculares nacionais para a educação das relações étnicoraciais e para o ensino de história e cultura afro-brasileira e africana. Brasília: MEC, 2004.

CASTRO-GOMES, Santiago. Decolonizar la universidad: la hybris del punto cero y el diálogo de saberes. In: CASTRO-GOMES, Santiago y Grosfoguel, Ramón (Org.). El giro decolonial: reflexiones para una diversidad epistémica más allá del capitalismo global. Bogotá: Siglo del Hombre Editores; Universidad Central, Instituto de Estudios Sociales Contemporáneos y Pontificia Universidad Javeriana, Instituto Pensar, 2007, p. 79-92.

DIAWARA, Manthia; DIAKHATÉ, Lydie. Cinema africano: novas formas estéticas e políticas. Lisboa: Sextante Editora, 2011.

DUSSEL, Enrique. Hacia una filosofía política crítica. Bilbao, España: Desclée de Brouwer, 2001.

GRUPO de Estudios Sobre Colonialidad. Estudios Decoloniales: un panorama general. Revista KULA. Antropólogos del Atlántico Sur, Nº 6, p. 8 - 21, Abril 2012.

GROSFOGUEL, Ramón. Para descolonizar os estudos de economia política e os estudos pós-coloniais: Transmodernidade, pensamento de fronteira e colonialidade global.

Revista Crítica de Ciências Sociais [Online], 80 | URL : http://rccs.revues.org/697 ; DOI : 10.4000/rccs.697, 2008.

GUIMARÃES, Manoel Luis Salgado. Nação e civilização nos trópicos: o Instituto Histórico e Geográfico Brasileiro e o projeto de uma história nacional. Revista Estudos Históricos, n.1, p. 5-27, 1988.

HOUNTONDJ, Paulin J. Conhecimento de África, conhecimento de africanos: duas perspectivas sobre os estudos africanos. In: SANTOS, Boaventura de Sousa y MENESES, Maria Paula (Org.). Epistemologias do Sul. 2.ed. São Paulo: Editora Cortez, 2015, p. 131144.

KAYAPÓ, Edson. Brito, Tamires. A pluralidade étnico-cultural indígena na Brasil: o que a escola tem a ver com isso? Mneme Revista de Humanidades. Caicó, v. 15, n. 35, p. 38-68, jul./dez.,2014.

KI-ZERBO, Joseph. Para quando África? Rio de Janeiro: Pallas, 2006. 
LEITE, Ana Mafalda. Oralidades e escritas pós-coloniais: estudos sobre literaturas africanas. Rio de Janeiro: EdUERJ, 2012.

LUCIANO, Gersem José dos Santos. Entrevista. Revista História Hoje, Dossiê Ensino de História Indígena, v.1, n.2, p.127-148, 2012.

MBEMBE, Achille. Sair da grande noite: ensiaos sobre a África descolonizada. Angola/Portugal: Edições Mulemba/ Edições Pedago, 2014a.

MIGNOLO, Walter D. Histórias locais/Projetos globais: colonialidade, saberes subalternos e pensamento liminar. Belo Horizonte: UFMG, 2003.

MIGNOLO, Walter. A colonialidade de cabo a rabo: o hemisfério ocidental no horizonte conceitual da modernidade. In: LANDER, Edgardo (Org). A colonialidade do saber: eurocentrismo e ciências sociais: perspectivas latino-americanas. Buenos Aires: CLACSO, Consejo Latinoamericano de Ciencias Sociales, 2005, p.33-49.

MORTARI, Claudia. O "equilíbrio das histórias": reflexões em torno de experiências de ensino e pesquisa em História das Áfricas. In: PAULA, Simoni Mendes de; CORREA, Sílvio Marcus de Souza (Orgs.). Nossa África: ensino e pesquisa. São Leopoldo: Oikos, 2016, p. 41-53.

MUDIMBE, V. Y. A invenção da África: gnose, filosofia e a ordem do conhecimento. Portugal: Edições Pedago, 2013.

QUIJANO, Anibal. Colonialidade do poder, Eurocentrismo e América Latina. In: LANDER Edgardo, (Org). A colonialidade do saber: eurocentrismo e ciências sociais. Perspectivas latino-americanas. Buenos Aires: CLACSO, Consejo Latinoamericano de Ciencias Sociales, 2005, p.107-130.

RIBEIRO, Marcelo. O cinema político africano e o direito de narrar. In: Cine África, 8 de abril de 2011. Disponível em: http://cine-

africa.blogspot.com.br/search?q=cinema+pol\%C3\%ADtico+africano. Acessado em: 15 de maio de 2017. 